This item was submitted to Loughborough's Research Repository by the author.

Items in Figshare are protected by copyright, with all rights reserved, unless otherwise indicated.

\title{
Use of the compulsive exercise test with athletes : norms and links with eating psychopathology
}

PLEASE CITE THE PUBLISHED VERSION

http://dx.doi.org/10.1080/10413200.2013.867911

\section{PUBLISHER}

Taylor and Francis (@ Association for Applied Sport Psychology)

VERSION

AM (Accepted Manuscript)

LICENCE

CC BY-NC-ND 4.0

\section{REPOSITORY RECORD}

Plateau, Carolyn R., Vaithehy Shanmugam, Rachel Duckham, Huw Goodwin, Sophia Jowett, Katherine S.F. Brooke-Wavell, Alex Laybourne, Jon Arcelus, and Caroline Meyer. 2019. "Use of the Compulsive Exercise Test with Athletes : Norms and Links with Eating Psychopathology”. figshare.

https://hdl.handle.net/2134/15236. 
This item was submitted to Loughborough's Institutional Repository (https://dspace.lboro.ac.uk/) by the author and is made available under the following Creative Commons Licence conditions.

\section{creative
commons}

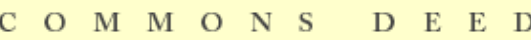

Attribution-NonCommercial-NoDerivs 2.5

You are free:

- to copy, distribute, display, and perform the work

Under the following conditions:

Attribution. You must attribute the work in the manner specified b the author or licensor.

Noncommercial. You may not use this work for commercial purposes.

No Derivative Works. You may not alter, transform, or build upon this work.

- For any reuse or distribution, you must make clear to others the license terms of this work.

- Any of these conditions can be waived if you get permission from the copyright holder.

Your fair use and other rights are in no way affected by the above.

This is a human-readable summary of the Leqal Code (the full license).

\section{Disclaimer 만}

For the full text of this licence, please go to: http://creativecommons.org/licenses/by-nc-nd/2.5/ 
1

2

Use of the Compulsive Exercise Test With Athletes:

3

Norms and Links With Eating Psychopathology

4

5 Carolyn R Plateau, Vaithehy Shanmugam, Rachel L Duckham, Huw Goodwin, Sophia Jowett, 6 Katherine S F Brooke-Wavell, Alex Laybourne, Jon Arcelus and Caroline Meyer

7

Loughborough University

8

9

10

11 
2 This study assessed the 5 factor structure of the Compulsive Exercise Test and explored the

3 relationship between compulsive exercise and eating psychopathology in athletes.

4 Confirmatory and exploratory factor analyses of the Compulsive Exercise Test were

5 conducted with 689 competitive athletes (aged 18 to 35 years). Convergent validity with the

6 Eating Disorders Examination Questionnaire was explored. The 5 factor structure showed a

7 poor fit; an alternative 3 factor structure is proposed. Exercising for weight control and to

8 avoid a negative mood were strongly associated with eating psychopathology. Implications

9 for using the Compulsive Exercise Test with athletes are discussed. 
1

2

3

4 development and maintenance of eating psychopathology (Davis et al., 1997; Davis, Katzman

5 \& Kirsh, 1999). Many patients report being involved in sport prior to dieting and levels of

6 activity have been found to significantly increase prior to onset and during the acute phase of

7 an eating disorder (Davis, Kennedy, Ralevski \& Dionne, 1994). Exercise among eating

8 disordered patients can also have a negative impact on treatment outcome (Dalle Grave,

9 Calugi \& Marchesini, 2008), with exercising patients more likely to relapse (Carter,

10 Blackmore, Sutandar-Pinnock \& Woodside, 2004) and require longer hospitalization

11 (Solenberger, 2001). Further evidence for the association between exercise and eating psychopathology comes from the significantly increased prevalence of eating psychopathology among athletes (Byrne \& McLean, 2002; Torstveit, Rosenvinge \& SundgotBorgen, 2008). These studies, involving a two-stage process of screening and subsequent clinical interview, have found that up to $20 \%$ of female and $8 \%$ of male elite athletes meet the criteria for an eating disorder (Sundgot-Borgen \& Torstveit, 2004). Athletes competing in lean sports (endurance, aesthetic, and weight dependent sports) are considered most at risk (Smolak, Murnen, \& Ruble, 2000; Torstveit et al., 2008). The incidence of eating disorders among athletes competing at sub-elite levels is difficult to establish due to differences in the methods used to define this group of athletes. There is, however, evidence to suggest a protective effect of competing in sport at a non-elite level, with lower levels of eating psychopathology indicated in comparison to elite athletes (Byrne \& McLean, 2001; Picard, 1999; Smolak et al. 2000). 
Identifying athletes who are vulnerable to developing an eating disorder remains a

2 challenge for clinicians and sports professionals alike (Thompson \& Sherman, 2010). This is

3 due to several factors, such as sport body stereotypes, which can foster expectations for

4 athletes to be a particular size and shape. For example, coaches may expect distance runners

5 and gymnasts to be slim and thus may experience difficulties in noticing weight loss among

6 these athletes (Thompson \& Sherman, 1999). Similarly, eating disorder symptoms such as

7 amenorrhea may be perceived as normal among athletes (Sherman, Thompson, Dehass \&

8 Wilfert, 2005), and therefore not prompt early investigation into a potential eating problem.

9 Moreover, coaches and sports professionals also report lacking in confidence and knowledge

10 when identifying the early signs and symptoms of eating problems among athletes (Vaughan,

11 King, \& Cottrell, 2004). Lastly, a fundamental issue lies with differentiating between athletes engaging in unhealthy exercise that could indicate an eating disorder, and those who are merely committed to training (Thompson \& Sherman, 2010). Some possible reasons for this will be considered, alongside an exploration of an alternative model for exercise in the eating disorders, and its potential to assist in distinguishing athletes at risk.

A primary difficulty in identifying athletes engaging in unhealthy exercise behaviors

17 lies with the traditional view that the functional utility of exercise within the eating disorders is primarily for calorie burning, weight and shape control (Fairburn, Cooper \& Shafran, 2003). Such conceptualizations prompted investigations into the frequency and duration of exercise that might engender an increased risk for eating disorders (Davis, 1997; 2000). However,

21 there has been little agreement about how much exercise is excessive (Davis \& Kaptein, 2006;

22 Shroff et al., 2006), and exercise quantity has not been found to be related to eating psychopathology (Mond, Myers, Crosby, Hay \& Mitchell, 2008; Taranis, Touyz \& Meyer,

24 2011). Moreover, a definition of problematic exercise that focuses on the duration and 25 frequency of exercise may bear little relevance for athletes. In order to successfully identify 
1 unhealthy exercising attitudes and behaviors among athletes, it is necessary to consider an

2 alternative definition of exercise that incorporates cognitive behavioral maintenance factors

3 of exercise, in addition to weight control.

4

5

6

7

8

9

One such multidimensional model of compulsive exercise within the eating disorders has recently been proposed (Meyer, Taranis, Goodwin \& Haycraft, 2011; Taranis et al., 2011). In addition to exercising for weight control, the model also incorporates additional cognitive behavioral maintenance components of compulsive exercise, such as exercising for positive and negative affect regulation, exercise rigidity and compulsivity to exercise despite a lack of enjoyment. The evidence for each of these components will be considered in more depth.

First, the inability to cope with adverse mood has been identified as an important maintenance factor for eating disorders, with dysfunctional mood regulatory behaviors often employed to normalize negative mood states (Fairburn et al., 2003). Compulsive exercise has been proposed as one of these mood regulation strategies (Meyer et al., 2011), maintained primarily by negative reinforcement mechanisms (Bratland-Sanda et al., 2010b; De Young \& Anderson, 2010; Penas-Lledo, Vaz Leal \& Waller, 2002). Exercising to control weight, shape, and appearance have previously been identified as primary motivations for exercise in the eating disorders (Dalle Grave et al., 2008, Davis et al., 1994); however negative affect regulation has recently been cited as an important reason for exercise by eating disordered patients (Bratland-Sanda et al., 2010a). It is plausible to suggest that affect regulation may be perceived as a more socially acceptable reason for exercise, however there is evidence to suggest a role of exercising for negative affect regulation in the etiology and maintenance of eating disorders (Holtkamp, Hebebrand \& Herpertz-Dahlmann, 2004; Thome \& Espelage, 2004). Specifically, reductions in eating psychopathology in patients have been found to correlate with a reduction in the perceived importance of exercising to regulate negative affect, but not with weight control exercise (Bratland-Sanda et al., 2010b). Furthermore, 
1 negative affect but not exercising for weight control, was found to be a significant predictor

2 of exercise dependence in both patients and controls (Bratland-Sanda et al., 2011).

3

4

Second, exercise rigidity is an important component of compulsive exercise (Yates, 1991) and is a strong predictor of eating psychopathology (Boyd, Abraham \& Luscombe, 2007). Rigidity is closely linked with dysfunctional perfectionism (Riley \& Shafran, 2005), which is associated with higher levels of compulsive exercise in both non-clinical and clinical groups (Shroff et al., 2006; Taranis \& Meyer, 2010). Exercise rigidity can manifest as an inability to reduce exercise routines, experiencing significant distress when exercise is interrupted, or exercising despite malnourishment, injury, or illness (Bamber, Cockerill, Rodgers \& Carroll, 2003; Boyd et al., 2007). Rigidity is also an important component of obsessive compulsive personality disorder, which is closely associated with eating disorders (Halmi, 2005). It has been suggested that repetitive exercise behavior may have an anxiolytic effect (Holtkamp et al., 2004), and is thus closely linked to the compulsive facet of the model.

The compulsivity component of the proposed multidimensional model (Meyer et al., 2011) is underpinned by findings that compulsive exercise has an anxiety-reducing function, analogous to the utility of compulsive behaviors observed among patients with obsessivecompulsive disorder (Davis \& Kaptein, 2006). Moreover, compulsively exercising patients score very high on measures of compulsivity (Davis \& Claridge, 1998). Feelings of intense guilt when exercise is missed or postponed have also been commonly reported among compulsive exercisers (Mond et al., 2008), serving to maintain driven and rigid exercise routines. In addition, these pathological attitudes towards exercise have been found to mediate the relationship between exercise and eating psychopathology (Cook \& Hausenblas, 2008).

The proposed multidimensional model of compulsive exercise (Meyer et al., 2011) may be of particular use in detecting unhealthy attitudes and behaviors towards exercise in an 
1 athletic population, where distinguishing such exercise has been identified as a particular

2 challenge (Thompson and Sherman, 2010). Using an exercise based measure to assess eating

3 psychopathology has been previously conducted among exercisers (Davis, Brewer \& Ratusny,

4 1993; Yates, Edman, Crago \& Crowell, 2001), however exercise in athletes has not been

5 measured in a multifaceted way that fits with the eating disorder conceptualization. It is

6 reasonable to extend such an approach to the athletic population, given the high prevalence

7 rates of eating psychopathology within this group. An exercise measure may be more

8 willingly received by athletes than an explicit eating disorder measure, as evidence has

9 suggested that athletes may distort their responses on eating measures (Sundgot-Borgen,

10 1993), perhaps due to fear of being stopped from training, losing their sponsorship funding or

11 school scholarship (Yates et al., 2001). It is acknowledged that an exercise measure may lack

12 the specificity of an eating measure; however, assessing and subsequently addressing

13 unhealthy exercise behaviors and attitudes may facilitate prevention of eating disorders in

14 athletes.

The Compulsive Exercise Test was developed in accordance with the outlined

multidimensional model of compulsive exercise, (Taranis et al., 2011). Factor analysis

17 revealed five factors explaining $64 \%$ of the variance in eating psychopathology. These factors encapsulate the model components of exercising for mood regulation, weight control exercise, compulsivity and exercise rigidity. They were labeled (a) Avoidance and Rule Driven

Behavior, (b) Weight Control Exercise, (c) Mood Improvement, (d) Lack of Exercise

21 Enjoyment, and (e) Exercise Rigidity. The factors have been replicated in male and female

22 adolescents (Goodwin, Haycraft, Taranis \& Meyer, 2011), and test scores were found to be

23 strongly associated with eating psychopathology scores (Goodwin et al., 2011; Taranis et al.,

24 2011). The multidimensional model of compulsive exercise, as proposed by Meyer and

25 colleagues (2011), has yet to be assessed in athletes. 
1

2

3

4

5

\section{Participants}

In summary, there is a wealth of evidence that supports additional cognitivebehavioral maintenance components of compulsive exercise. Athletes are at a significantly increased risk of eating psychopathology, although difficulties remain in identifying athletes engaging in unhealthy exercise, which can precede the development of an eating disorder.

The Compulsive Exercise Test could facilitate the detection of exercise attitudes and behaviors that engender an increased vulnerability to eating disorders among athletes. The primary aim of this study was therefore to evaluate the five factor structure of the Compulsive Exercise Test in a sample of competitive athletes. It is predicted that compulsive exercise will be significantly, positively associated with eating psychopathology.

\section{Method}

Following ethical clearance granted through the Institutional Ethical Advisory Committee, 702 competitive athletes ( $n=258$ males), were recruited from sports clubs and teams at British universities. For the purpose of this study, athletes were required to meet specific inclusion criteria to be eligible to take part: to be currently competing in, and training for, a particular sport, and to have been doing so for a minimum of six months. Participants who reported engaging in noncompetitive sport were therefore removed ( $n=13)$, leaving a total of 689 participants. Fifteen participants reported a current or previous eating disorder. The ages of the participants ranged from 18 to 35 years, with a mean of the female participants 21.20 years $(S D=3.46)$ and 21.21 years $(S D=3.01)$ for males. The mean BMI for females was $21.30 \mathrm{~kg} / \mathrm{m}^{2}(S D=2.44)$, and $24.49 \mathrm{~kg} / \mathrm{m}^{2}(S D=3.25)$ for the male participants. Sport classifications were made according to the system employed by Torstveit \& Sundgot-Borgen (2005) to ensure concordance with other studies within the literature. The sample was relatively evenly split between participants in lean (44\%) and nonlean (56\%) 
1 sports. The vast majority of the lean sport athletes competed in endurance sports, such as

2 distance running \& triathlon (88\%), with small numbers competing in aesthetic (3\%), weight

3 dependent (4\%) and antigravitational sports (5\%). Similarly, most of the athletes within the

4 nonlean category reported competing in ball sports (91\%), with small numbers competing in

5 power sports, such as sprinting (7\%) and technical sports such as golf (2\%). With regards to

6 competitive level, just under a third of the sample (30\%) was classified as elite, reporting that

7 they currently competed at national or international level. A further 33\% were classified as

8 sub-elite, competing for their region or university, and 19\% reported competing for their club

9 or county. A sizable proportion of competition level data was missing for this sample (19\%).

10 Participants completed the Compulsive Exercise Test (Taranis et al., 2011) and the Eating

11 Disorders Examination Questionnaire (Fairburn \& Beglin, 2008). When answering questions

12 about their exercise attitudes and behaviours, participants were instructed to consider exercise

13 as any form of physical exercise, whether as part of an instructed exercise schedule or

14 recreational exercise.

15 Materials

The Compulsive Exercise Test (Taranis et al., 2011). The Compulsive Exercise

17 Test is a 24-item self-report measure based on the multidimensional model of compulsive

18 exercise, designed for use in the eating disorders domain. It has five subscales: (a)

19 Avoidance and Rule Driven Behavior, (b) Weight Control Exercise, (c) Mood Improvement

20 (d) Lack of Exercise Enjoyment, and (e) Exercise Rigidity. An example item is "If I cannot

21 exercise, I feel anxious.” Responses are scored on a six-point scale anchored from 0 (never

22 true) to 5 (always true); intermediate response points are 1 (rarely true), 2 (sometimes true),

233 (often true), and 4 (usually true). Higher scores indicate a greater degree of compulsive

24 exercise. The global score is the sum of the means of the five individual subscales. The

25 Compulsive Exercise Test has shown good internal consistency for the individual subscales 
$1 \quad(\alpha \geq 0.71)$ and global score $(\alpha \geq 0.85)$ among both adult and adolescent samples (Goodwin et

2 al., 2011; Taranis et al., 2011).

The Eating Disorders Examination Questionnaire 6.0 (Fairburn \& Beglin, 2008).

This is a 28-item self-report measure derived from the Eating Disorders Examination; an investigator based interview schedule considered to be the gold standard in assessing eating disorders. The Eating Disorders Examination Questionnaire has shown high internal consistency ( $\alpha=0.85$ ) and test-retest reliability, Pearson's $r=0.81$ - 0.94 (Luce \& Crowther, 1999). It uses a 7-point forced choice rating scheme, exploring eating behaviors and attitudes in the preceding 28 days, anchored by 0 (No days) and 6 (Every day). It has four subscales: (a) Restraint, (b) Eating Concern, (c) Shape Concern, and (d) Weight Concern. An example item is "Have you been deliberately trying to limit the amount of food you eat to influence your shape and weight?” The Global Score is the mean of the four individual subscales. The questionnaire has previously been used with athletes to assess eating psychopathology (Sundgot-Borgen \& Torstveit, 2004; Shanmugam, Jowett \& Meyer, 2011). Cronbach alpha coefficients in this study were (a) Restraint .78, (b) Eating Concern .82, (c) Shape Concern .92, (d) Weight Concern .85, and (e) Global Score .91.

\section{Data Analysis}

The data were assessed for univariate and multivariate normality and screened for outliers. Three multivariate outliers were identified and removed $\left(d^{2}=88.93 ; 81.14 ; 80.65\right.$; $p 1<0.00 ; p 2<0.00$ in all cases). Six hundred and eighty six cases remained. Mardia’s normalized estimate of multivariate kurtosis (1974) was found to be 82.35 , with a critical ratio of 30.53; values greater than 5.00 (Bentler, 2005) are suggested to be non-normally distributed. Hence, bootstrapping procedures were applied to account for the non-normality of the data. Overall model fit was assessed using the Bollen-Stine corrected $p$ value. Previous research has suggested that the five factor structure is appropriate for both males 
1 and females and for adults and adolescents (Goodwin et al., 2011; Taranis et al., 2011); hence

2 the data were not separated for the analysis.

3

4

Confirmatory Factor Analysis was employed to examine the fit of the five factor model in this athlete sample. The analysis was conducted using IBM AMOS 20, employing the Maximum Likelihood Estimation procedure. Multiple goodness of fit indices were used to assess the factorial validity of the model including the significance of $\chi^{2}$, the normed chisquare, the Root Mean Square Error of Approximation (RMSEA), Tucker Lewis Index (TLI), Incremental Fit Index (IFI) and the Comparative Fit Index (CFI). An RMSEA value of $<.06$ indicates a good fitting model (Hu \& Bentler, 1999), and values of greater than .95 are considered a good fit of data for the remaining indices (Hu \& Bentler, 1999). A cutoff of $\geq .40$ was used to identify significant factor loadings (Ford, MacCallum \& Tait, 1986).

Data that demonstrated poor fit were submitted to a principal components exploratory factor analysis, with direct oblimin (oblique) rotation. Oblique rotation was employed as it was expected that the factors would be correlated as they are assessing components of the same underlying compulsive exercise construct (Taranis et al., 2011). The sample size of 686 could be considered 'very good' for a factor analysis (>500, Comrey \& Lee, 1992). Missing data were replaced with the means for the individual, and not the sample, to avoid reducing the sample variance (Hill \& Lewicki, 2005). The analysis was conducted in SPSS 21.0.

\section{Results}

\section{Confirmatory Factor Analysis of the Compulsive Exercise Test Five Factor Structure}

Factor loadings for the items are shown in Figure 1. Item 8 "I do not exercise to be slim", and Item 12 "I enjoy exercising", did not meet the cutoff of $\geq .40$, so were removed from further analysis. The five factor model showed a poor fit to the data, failing to 
1 sufficiently meet the goodness of fit criteria: $\chi^{2}(199)=1196.55, p<.001$, RMSEA $=0.086$,

2 (90\% CI $[0.081,0.090]), \mathrm{TLI}=.79, \mathrm{IFI}=.82$, and CFI $=.82$. The Bollen-Stine corrected $p$

3 was significant $(p<0.001)$. Most of the latent variables were found to significantly co-vary

4 with one another (Figure 1); however, the paths between Lack of Exercise Enjoyment and

5 Exercise Rigidity and between Avoidance and Rule Driven Behavior and Lack of Exercise

6 Enjoyment did not. Removing the nonsignificant paths did not improve the overall fit.

An exploratory principal components analysis was considered appropriate to examine alternative model structures for the athlete sample. The analysis was conducted with the same participant group as for the Confirmatory Factor Analysis. This sequence of analysis has previously been reported by numerous published articles, where fit criteria were not met for CFA models (Darcy, Hardy, Crosby, Lock \& Peebles, 2013; Lampard, Byrne, McLean \& Fursland, 2011; Raykos, Byrne \& Watson, 2009).

\section{Exploratory Analysis of the Compulsive Exercise Test in Athletes}

The exploratory principal components analysis was initially conducted separately for males and females, lean and nonlean athletes, and older and younger athletes (via a median split); no differences were found in the factor structure between these groups, so the data was subsequently analyzed as a whole. The data was not separated by competitive level due to the significant proportion of missing data.

Sufficient inter-item correlations existed, with 21 of the 24 items correlating with at least one item (>0.3, Tabachnick \& Fidell, 2001). The three items that did not correlate sufficiently were (a) Item 3 "I like my days to be organised and structured of which exercise is just one part”, (b) Item 8 “I do not exercise to be slim”, and (c) Item 12 "I enjoy exercising” (Taranis et al., 2011). These items were removed from subsequent analysis. The Kaiser-Meyer-Olkin test was employed as a measure of sampling adequacy (MSA $=0.86$ ), 
1 indicating that inter-item correlations were compact. Bartlett's test of sphericity was also

2 significant, $X^{2}(210)=5456, p<0.001$.

Factor structure. The retention of factors was determined by a number of criteria.

4 First, the Kaiser (1961) criterion of eigenvalues greater than one indicated a five factor

5 solution that explained $61 \%$ of the variance. However, Horn's parallel analysis (Horn, 1965)

6 suggested a four factor solution, and scree plot analysis (Cattell, 1966) suggested a three

7 factor solution. Ambiguity between the factor retention criteria required inspection of the

8 communalities and the factor coefficients to determine the items that could be retained (Field,

9 2005). The average communalities for the three solutions were very similar: (a) the five

10 factor solution .61, (b) the four factor solution .59, and (c) the three factor solution .60.

A cutoff of $\geq .40$ was implemented to identify significant factor coefficients (Ford et al., 1986); items that failed to meet this cutoff were removed. Item 11 "I usually continue to exercise despite injury or illness, unless I am very ill or too injured” and Item 15 "If I miss an exercise session, I will try and make up for it when I next exercise”, were therefore removed from further analysis. Factors with fewer than two items were deemed to be unstable, therefore these items were also removed (Pallant, 2007). This included (a) Item 7 “My weekly pattern of exercise is repetitive”, (b) Item 19 “I follow a set routine for my exercise sessions”, (c) Item 5 “I find exercise a chore”, and (d) Item 21 "I do not enjoy exercising." Principal components analysis with oblique rotation was conducted with the remaining items, resulting in a three factor solution that explained $59.90 \%$ of the variance (Table 1 ). interpretation. Factor 1 included six items, all of which were related to the avoidance of negative feelings that are experienced when exercise is missed. An example of an item loading onto Factor 1 was Item 9: “If I cannot exercise I feel low or depressed.” This was 
1 Rule Driven Behavior as identified by Taranis et al. (2011), thus was labeled Avoidance of

2 Negative Affect. Two items were missing from the original subscale-Item 11 and Item 15-

3 which were removed at an earlier stage of analysis.

4

5

6

7

8

9

The four items loading onto Factor 2 were related to exercising to improve appearance or for weight and shape reasons. An example of one of the items loading onto this factor is Item 18: "I exercise to burn calories and to lose weight.” This corresponds with the Weight Control Exercise subscale of the original Compulsive Exercise Test, although is missing Item 8, which was excluded earlier in the analysis. The Weight Control Exercise label was retained for this subscale.

The five items loading onto Factor 3 were related to the positive mood improvements associated with exercise. An example of an item loading on Factor 3 was Item 1: "I feel happier and/or more positive after I exercise.” The items loading onto this factor are identical to those on the Mood Improvement subscale identified by Taranis et al. (2011); this label was therefore retained. In summary, 15 items remain from the Compulsive Exercise Test after exploratory principal components analysis, with three subscales retained.

\section{Internal Consistency of the Compulsive Exercise Test}

The internal consistency of the three factors was established using reliability analysis.

Alpha coefficients were (a) Avoidance of Negative Affect .87, (b) Weight Control

Exercise .82, (c) Mood Improvement .71, and (d) Global Score .62. Means and standard deviations for the three and five factor Compulsive Exercise Test subscales are given in Table 2. Means (with standard deviations in parantheses) for the Eating Disorders Examination Questionnaire subscales were (a) Restraint, $M=1.31$ ( $S D=1.30$ ); (b) Eating Concern, $M=$ 0.68 (SD = 1.04); (c) Shape Concern $M=1.71$ (SD = 1.53); (d) Weight Concern, $M=1.37$ $(S D=1.42)$; and (e) Global Score, $M=1.27(S D=1.19)$ 


\section{Convergent Validity With the Eating Disorders Examination Questionnaire}

Correlation analysis. To assess the convergent validity of the Compulsive Exercise

3 Test with an established measure of eating psychopathology, a series of one-tailed

4 Spearman's rho correlations were conducted between the proposed three factor Compulsive

5 Exercise Test and the Eating Disorders Examination Questionnaire. Strong positive

6 correlations existed between all eating psychopathology subscales and (a) Weight Control

7 Exercise, $r(685) \geq .53, p<0.01$; (b) Avoidance of Negative Affect, $r(685) \geq .31, p<0.01$;

8 and (c) Global Score, $r(685) \geq .47, p<0.01$. Smaller positive correlations were observed for

9 the Mood Improvement subscale, $r(685) \geq .16, p<0.01$.

Regression analysis. Stepwise regression analysis was conducted to assess the proportion of variance in Eating Disorder Examination Questionnaire scores that could be explained by scores on the three factor Compulsive Exercise Test. Gender, age, BMI, sporttype (lean or nonlean) and competitive level were also included as possible predictors, although only gender was retained as significant predictor for eating psychopathology scores. The total variance in eating psychopathology scores that could be explained by the regression model was 44\%. The Weight Control Exercise subscale from the Compulsive Exercise Test could account for the largest amount of variance in Eating Disorders Examination Questionnaire scores (39\%); the Avoidance of Negative Affect subscale accounted for a small, but significant, proportion of the variance (4\%). The Mood Improvement subscale was not retained as a significant predictor (Table 3).

\section{Discussion}

This study aimed to evaluate the five factor structure of the Compulsive Exercise Test in an athlete sample, and to explore the relationship between compulsive exercise and eating psychopathology. The findings indicated that the five factor structure of the Compulsive 
1 Exercise Test represented a moderately good fit for the athlete sample. Exploratory analysis

2 resulted in an alternative 15 item, three factor Compulsive Exercise Test. The factors were

3 labeled (a) Avoidance of Negative Affect, (b) Weight Control Exercise, and (c) Mood

4 Improvement. The Exercise Rigidity and Lack of Exercise Enjoyment subscales that have

5 previously been validated in adolescent and female exercisers (Goodwin et al., 2011; Taranis

6 et al., 2011) were not retained in this study. In support of the hypothesis, compulsive

7 exercise and eating psychopathology scores were significantly and positive associated.

8 Specifically, the Weight Control Exercise and Avoidance of Negative Affect subscales were

9 found to explain a significant proportion of the variance in eating psychopathology scores.

The findings support a multidimensional model of compulsive exercise in athlete

11 groups (Meyer et al., 2011). In addition to exercising for weight control, which has been consistently reported as an important motivation for exercise within the eating disorders

13 (Fairburn et al., 2003), Avoidance of Negative Affect was identified as a core component of

14 compulsive exercise among athletes. Compulsive exercise has been identified as a mood

15 regulatory strategy, which is dysfunctional when maintained by negative reinforcement

16 mechanisms (Meyer et al., 2011), and these findings indicate that exercise in athletes may

17 also sometimes serve this function. Exercise can also be maintained by positive

18 reinforcement mechanisms, as indicated by the retention of the Mood Improvement subscale.

19 However, the Exercise Rigidity and Lack of Exercise Enjoyment components of compulsive

20 exercise are likely to be less relevant for athletes. Indeed, the rule driven behavior

21 component of the original Avoidance and Rule Driven Behavior subscale was dropped from

22 the three factor model. Athlete exercise schedules are likely to be highly repetitive, habitual

23 and performance oriented, particularly among those competing at an elite level. Such

24 schedules may also be externally regulated or supervised by a coach. It is plausible that rigid,

25 self-imposed exercise schedules that lack external regulation or specific performance goals 
1 may be more closely aligned with eating psychopathology. This suggests a need to explore

2 internally motivated and externally imposed exercise rigidity in relation to eating

3 psychopathology in athletes.

4

The Lack of Exercise Enjoyment subscale was also not retained for this sample. This may be surprising given that highly strenuous exercise is rarely associated with mood improvement (Reed \& Buck, 2009) even when controlling for goal orientation (Motl, Berger \& Wilson, 1996). However, the positive effects of exercise on mood are more likely to occur in those who exercise regularly (Hoffman \& Hoffman, 2008), and athletes are likely to experience enjoyment when exercising with others or when working towards performance goals (McCarthy, Jones \& Clark-Carter, 2008; Scanlan, Carpenter, Lobel \& Simons, 1993).

It is important to note that the original Exercise Rigidity and Lack of Exercise Enjoyment subscales had only three items and may have lacked initial stability (Pallant, 2007). The proposed factor structure requires replication with additional athlete samples, but this study suggests that the subscales of Lack of Exercise Enjoyment and Exercise Rigidity need to be interpreted with caution with athlete groups.

A significant strength of this study is the large sample of competitive athletes that were included. The sample did, however, pose some limitations to the conclusions that can be drawn from this study. The majority of the samples in both studies were endurance athletes and ball sport players, and participant groups for the two studies were not equal in terms of the percentage of lean and non-lean athletes. Competitive level data was also missing for a significant proportion of the sample, and it is acknowledged that this could have a significant impact both on the interpretation of the results (Acuna \& Rodriguez, 2004) and in reducing the replicability of the study. The data were not separated by competitive level for the exploratory analysis, due to the proportion that was missing, however the literature exploring the impact of competitive level on eating psychopathology in athletes has been 
1 somewhat inconclusive (Picard, 1999; Smolak et al., 2000; Toro et al., 2005). It was therefore

2 not considered problematic to explore the sample as a whole within this study. However, it is

3 an important avenue for future work to compare compulsive exercise across athletes at

4 differing competitive levels. This is important as it is plausible to suggest that competition

5 intensity and training level may be an important factor in both levels of compulsive exercise

6 and the relationship between compulsive exercise and eating psychopathology.

7

8 lean sports, and for athlete groups for which there were low numbers for this study -

9 aesthetic, power, technical and weight-dependent athletes. It is important to assess whether the three factor structure of the Compulsive Exercise Test is relevant for athletes outside of ball sports and endurance sports. In addition, it is recommended that invariance testing for gender, competitive level and age is conducted to further validate the proposed athlete model. The variance in eating psychopathology accounted for by the Compulsive Exercise Test subscales was lower than in previous studies (Goodwin et al., 2011; Taranis et al., 2011). Additional factors could account for some of the variance that is not captured by the Compulsive Exercise Test, notably perfectionism. An important next step would therefore be the inclusion of a validated measure of perfectionism to assess the relationship with eating psychopathology and compulsive exercise in athlete groups. Further improvements are also needed in determining the relationship between eating psychopathology and compulsive exercise in athlete groups. One way to do this would be to use the Eating Disorders Examination (Fairburn \& Cooper, 1993) to establish eating disorder diagnosis. Longitudinal investigations would help to establish the direction of the relationship between compulsive exercise and eating psychopathology in athletes.

This study provides support for the multidimensional model of compulsive exercise in athletes, indicating a particularly strong relationship between exercising for weight control 
1 and for mood regulation with eating psychopathology. The original five factor structure of

2 the Compulsive Exercise Test showed a poor fit; a three factor structure may be more

3 appropriate when assessing and comparing athlete groups. In particular, this study suggests

4 that the Exercise Rigidity and the Lack of Exercise Enjoyment subscales may be less relevant

5 for athletes, and thus should be interpreted with caution by researchers and clinicians.

6 The Weight Control Exercise, Avoidance of Negative Affect and Mood Improvement

7 subscales may potentially provide a valid method of assessment of athletes on cognitive

8 behavioral features of compulsive exercise. The Compulsive Exercise Test may therefore be

9 an important, and useful, tool for sport psychologists and other practitioners working within

10 the sports context to detect unhealthy attitudes towards exercise among athletes. The

11 Compulsive Exercise Test can be used as a screening measure due to its ease of

12 administration and facilitate practitioners in detecting athletes who are motivated to exercise

13 for weight control and mood regulation; factors which are strongly associated with increased

14 eating problems. As a measure of exercise attitudes and behaviours, the Compulsive Exercise

15 Test may also be more readily received and completed by athletes in comparison to a

16 measure of eating psychopathology. This study makes an important contribution to the

17 literature in exploring the concept of compulsive exercise within an athlete sample. The

18 findings can inform the development and tailoring of eating disorder therapies that are

19 specific to the needs of athletes; which do not currently exist. 
2 Acuna, E., \& Rodriguez, C. (2004). The Treatment of Missing Values and its Effect on

3

4

5

6

7

8

9

10 Classifier Accuracy. In D.L.Banks, F.R. McMorris, Arabie, P., \& W. Gaul (Eds). Classification, Clustering and Data Mining Applications. Berlin: Springer

Bamber, D., Cockerill, I.M., Rodgers, S., \& Carroll, D. (2003). Diagnostic criteria for exercise dependence in women. British Journal of Sports Medicine, 37, 393-400. doi:10.1136/bjsm.37.5.393

Bentler, P.M (2005). EQS 6 structural equations program manual. Encino, CA: Multivariate Software.

Boyd, C., Abraham, S., \& Luscombe, G. (2007). Exercise behaviours and feelings in eating disorder and non-eating disorder groups. European Eating Disorder Review, 15, 112118. doi: 10.1002/erv.769.

Bratland-Sanda, S., Sundgot-Borgen, J., RØ, O., Rosenvinge, J.H., Hoffart, A., \& Martinsen, E.W. (2010a). “I’m not physically active...I only go for walks”: Physical activity in patients with longstanding eating disorders. International Journal of Eating Disorders, 43, 88-92. doi: 10.1002/eat.20753.

Bratland-Sanda, S., Sundgot-Borgen, J., RØ, O., Rosenvinge, J.H., Hoffart, A., \& Martinsen, E.W. (2010b). Physical activity and exercise dependence during inpatient treatment of longstanding eating disorders: An exploratory study of excessive and non-excessive exercisers. International Journal of Eating Disorders, 43, 266-273. doi: 10.1002/eat.20769.

Bratland Sanda, S., Martinsen, E.W., Rosenvinge, J.H., Ro, O., Hoffart, A., \& SundgotBorgen, J. (2011). Exercise dependence score in patients with longstanding eating 
disorders and controls: The importance of affect regulation and physical activity intensity. European Eating Disorders Review, 19, 249-255.

Byrne, S., \& McLean, N. (2002). Elite athletes: Effects of the pressure to be thin. Journal of Science \& Medicine in Sport, 5, 80-94. doi:10.1016/S1440-2440(02)80029-9

Carter, J.C., Blackmore, E., Sutandar-Pinnock, K., \& Woodside, D.B. (2004). Relapse in anorexia nervosa: A survival analysis. Psychological Medicine, 34, 671-679. doi: $10.1017 / \mathrm{S} 0033291703001168$

Catell, R.B. (1966). The scree test for the number of factors. Multivariate Behavioral Research, 1, 245-276. doi:10.1207/s15327906mbr0102_10

Comrey, A.L., \& Lee, H.B. (1992). A first course in factor analysis. Hillsdale, NJ: Erlbaum.

Cook, B.J., \& Hausenblas, H.A. (2008). The role of exercise dependence for the relationship between exercise behavior and eating pathology: Mediator or moderator? Journal of Health Psychology, 13, 495-502. doi: 10.1177/1359105308088520

Darcy, A.M., Hardy, K.K., Crosby, R.D., Lock, J., \& Peebles, R. (2013). Factor structure of the Eating Disorder Examination Questionnaire (EDE-Q) in male and female college athletes. Body Image, 10, 399-405. doi: 10.1016/j.bodyim.2013.01.008

Dalle Grave, R., Calugi, S., Marchesini, G. (2008). Compulsive exercise to control shape or weight in eating disorders: Prevalence, associated features and treatment outcome. Comprehensive Psychiatry, 49, 346-352. doi:10.1016/j.comppsych.2007.12.007

Davis, C. (1997). Eating disorders and hyperactivity: A psychobiological perspective. Canadian Journal of Psychiatry, 42, 168-175.

Davis, C. (2000). Exercise abuse. International Journal Sport Psychology, 31, 278-289. 
1 Davis, C., Brewer, H., \& Ratusny, D. (1993). Behavioral frequency and psychological commitment: Necessary concepts in the study of excessive exercising. Journal of Behavioral Medicine, 16, 611-628. doi: 10.1007/BF00844722

Davis, C., \& Claridge, G. (1998). The eating disorders as addiction: A psychobiological perspective. Addictive Behaviors, 23, 463-475. doi: 10.1016/S0306-4603(98)00009-4

Davis, C., \& Kaptein, S. (2006). Anorexia nervosa with excessive exercise: A phenotype with close links to obsessive-compulsive disorder. Psychiatry Research, 142, 209-216. doi: 10.1016/j.psychres.2005.11.006

Davis, C., Katzman, D.K., Kaptein, S., Kirsh, C., Brewer, H., Kalmbach, K., Olmstead, M.F., Woodside, D.B., \& Kaplan, A.S. (1997). The prevalence of high-level exercise in the eating disorders: Etiological implications. Comprehensive Psychiatry, 38, 321-326. doi:10.1016/S0010-440X(97)90927-5

Davis, C., Katzman, D.K., \& Kirsh, C. (1999). Compulsive physical activity in adolescents with anorexia nervosa: A psychobehavioral spiral of pathology. Journal of Nervous and Mental Disease, 187, 336-342. doi: 10.1097/00005053-199906000-00002

Davis, C., Kennedy, S.H., Ralevski, E., \& Dionne, M. (1994). The role of physical activity in the development and maintenance of eating disorders. Psychological Medicine, 24, 957-967.doi: 10.1017/S0033291700029044

De Young, K.P., \& Anderson, D.A. (2010). Prevalence and correlates of exercise motivated by negative affect. International Journal of Eating Disorders, 43, 50-58. doi:10.1002/eat.20656

Fairburn, C.G., \& Beglin, S. (2008). Eating Disorder Examination Questionnaire (EDE-Q 6.0). In: Fairburn, C.G. Cognitive behavior therapy and eating disorders. New York: Guildford Press. 
1 Fairburn, C.G., \& Cooper, Z. (1993). The eating disorder examination. In C.G. Fairburn, \& G. T. Wilson (Eds.) Binge eating: Nature, assessment and treatment (pp. 317-360). New York: Guilford Press.

4 Fairburn, C.G., Cooper, Z., \& Shafran, R. (2003). Cognitive behavior therapy for eating disorders: A “transdiagnostic” theory and treatment. Behavior Research and Therapy, 41, 509-528. doi: 10.1016/S0005-7967(02)00088-8

7 Field, A. (2005). Discovering statistics using SPSS. (2 ${ }^{\text {nd }}$ Ed) Sage Publications Inc.

8 Ford, J.K, MacCallum, R.C., \& Tait, M. (1986). The application of exploratory factoranalysis in applied psychology: A critical review and analysis. Personnel Psychology, 39, 291-314. doi: 10.1111/j.1744-6570.1986.tb00583.x

Goodwin, H., Haycraft, E., Taranis, L., \& Meyer, C. (2011). Psychometric evaluation of the Compulsive Exercise Test (CET) in an adolescent population: Links with eating psychopathology. European Eating Disorders Review, 19, 269-279. doi: 10.1002/erv.1109

Halmi, K.A. (2005). Obsessive-compulsive personality disorder and eating disorders. Eating Disorders, 13, 85-92. doi: 10.1080/10640260590893683

Hill, T., \& Lewicki, P. (2005). Statistics: Methods and applications. Tulsa, OK: Statsoft.

Hoffman, M.D., \& Hoffman, D.R. (2008). Exercisers achieve greater acute exercise induced mood enhancement than non-exercisers. Archives of Physical Medicine and Rehabilitation, 89, 358-63. doi: 10.1016/j.apmr.2007.09.026

Holtkamp, K., Hebebrand, J., Herpertz-Dahlmann, B. (2004). The contribution of anxiety and food restriction on physical activity levels in acute anorexia nervosa. International Journal of Eating Disorders, 36, 163-171. doi:10.1002/eat.20035 
1 Horn, J.L. (1965). A rationale and test for the number of factors in factor analysis. Psychometrika, 30, 179-185. doi: 10.1007/BF02289447

3 Hu, L., \& Bentler, P.M. (1999). Cutoff criteria for fit indexes in covariance structure analysis: Conventional criteria versus new alternatives. Structural Equation Modeling, 1, 1-55.

Kaiser, H.F. (1961). A note on Guttman's lower bound for the number of common factors. British Journal of Mathematical and Statistical Psychology, 14, 249-276. doi: 10.1111/j.2044-8317.1961.tb00061.x

Lampard, A.M., Byrne, S.M., McLean, N., \& Fursland, A. (2011). Avoidance of affect in the eating disorders. Eating Behaviours, 12, 90-93. doi: 10.1016/j.eatbeh.2010.11.004

Luce, K.H., \& Crowther, J.H. (1999). The reliability of the Eating Disorder Examination self-report questionnaire version (EDE-Q). International Journal of Eating Disorders, 25, 349-351. doi: 10.1002/(SICI)1098-108X(199904)25:3<349::AIDEAT15>3.0.CO;2-M

Mardia, K.V. (1974). Applications of some measures of multivariate skewness and kurtosis in testing normality and robustness studies. Sankhya, B36, 115-128.

McCarthy, P.J., Jones, M.V., \& Clark-Carter, D. (2008). Understanding enjoyment in youth sport: A developmental perspective. Psychology of Sport and Exercise, 9, 142-156. doi: 10.1016/j.psychsport.2007.01.005

Meyer, C., Taranis, L., Goodwin, H., \& Haycraft, E. (2011). Compulsive exercise and eating disorders. European Eating Disorders Review, 19, 174-189. doi: 10.1002/erv.1122

Mond, J., Myers, T.C., Crosby, R., Hay, P., \& Mitchell, J. (2008). “Excessive exercise” and eating-disordered behavior in young adult women: Further evidence from a primary care sample. European Eating Disorders Review, 16, 215-221 doi: 10.1002/erv.855 
1 Motl, R.W., Berger, B.G., \& Wilson, T.E. (1996). Exercise intensity and the acute mood states of cyclists. Journal of Sport and Exercise Psychology, 18 (S59).

3 Pallant, J. (2007). SPSS survival manual: A step by step guide to data analysis using SPSS for Windows Version 15. Buckingham: Open University Press.

5 Picard, C.L. (1999). The level of competition as a factor for the development of eating disorders in female collegiate athletes. Journal of Youth and Adolescence, 28, 583-594. doi:10.1023/A:1021606710398

Raykos, B.C., Byrne, S.M., \& Watson, H. (2009). Confirmatory and exploratory factor analysis of the Distress Tolerance Scale (DTS) in a clinical sample of eating disorder patients. Eating Behaviors, 10, 215-219. doi:10.1016/j.eatbeh.2009.07.001

Reed, J., \& Buck, S. (2009). The effect of regular aerobic exercise on positive-activated affect: A meta-analysis. Psychology of Sport and Exercise, 10, 581-594. doi:10.1016/j.psychsport.2009.05.009

Riley, C., \& Shafran, R. (2005). Clinical perfectionism: A preliminary qualitative analysis. Behavioral and Cognitive Psychotherapy, 33, 369-374.doi: $10.1017 / \mathrm{S} 1352465805002122$

Scanlan, T.K., Carpenter, P.J., Lobel, M., \& Simons, J.P. (1993). Sources of enjoyment for youth sport athletes. Pediatric Exercise Science, 5, 275-285.

Smolak, L., Murnen S.K., \& Ruble, A.E. (2000). Female athletes and eating problems: A meta-analysis. International Journal of Eating Disorders, 27, 371-380. doi: 10.1002/(SICI)1098-108X(200005)27:4<371::AID-EAT1>3.0.CO;2-Y

Shanmugam, V., Jowett, S., \& Meyer, C. (2011). Application of the transdiagnostic cognitive behavioral model of eating disorders to the athletic population. Journal of Clinical Sport Psychology, 5, 166-191. 
1 Sherman, R.T., Thompson, R.A., Dehass, D., \& Wilfert, M. (2005). NCAA coaches survey: The role of the coach in identifying and managing athletes with disordered eating. Eating Disorders, 13, 447-466. doi: 10.1080/10640260500296707

4

Shroff, H., Reba, L., Thornton, I.M., Tozzi, F., Klump, K.L., Berrettini, W.H., Brandt, H., et al. (2006). Features associated with excessive exercise in women with eating disorders. International Journal of Eating Disorders, 39, 454-461. doi: 10.1002/eat.20247

Solenberger, S. (2001). Exercise and eating disorders: A 3-year inpatient hospital record analysis. Eating Behaviors, 2, 151-168. doi: 10.1016/S1471-0153(01)00026-5

Sundgot-Borgen, J. (1993). Prevalence of eating disorders in elite female athletes. International Journal of Sports Nutrition, 3, 29 - 40.

Sundgot-Borgen, J., \& Torstveit, M.K. (2004). Prevalence of eating disorders is higher amongst elite athletes than in the general population. Clinical Journal of Sports Medicine, 14, 25-32. doi: 10.1097/00042752-200401000-00005

Tabachnick, B.G., \& Fidell, L.S. (2001).Using Multivariate Statistics. Boston:Allyn \& Bacon.

Taranis, L., \& Meyer, C. (2010). Perfectionism and compulsive exercise among female exercisers: High personal standards or self-criticism? Personality and Individual Differences, 49, 3-7. doi: 10.1016/j.paid.2010.02.024

Taranis, L., Touyz, S., \& Meyer, C. (2011). Disordered eating and exercise: Development and preliminary validation of the Compulsive Exercise Test (CET). European Eating Disorders Review, 19, 256-268. doi: 10.1002/erv.1108

Thome, J. L., \& Espelage, D. L. (2004). Relations among exercise, coping, disordered eating, and psychological health among college students. Eating Behaviours, 5, 337-351. doi: 10.1016/j.eatbeh.2004.04.002 
1 Thompson, R.A., \& Sherman, R.T. (1999). Athletes, athletic performance and eating disorders: Healthier alternatives. Journal of Social Issues, 55, 317-337. doi: $10.1111 / 0022-4537.00118$

Thompson, R.A., \& Sherman, R.T. (2010). Eating disorders in sport. New York: Routledge.

5 Toro, J., Galilea, B., Martinez-Mallen, E., Salamero, M., Capdevila, L., Mari, J., Mayolas, J. Sports Medicine, 26, 693-700. Doi: 10.1055/s-2004-830378

Torstveit, M.K., Rosenvinge, J.H., \& Sundgot-Borgen, J. (2008). Prevalence of eating disorders and the predictive power of risk models in female elite athletes: A controlled study. Scandinavian Journal of Medicine and Science in Sports, 18, 108-118. doi: 10.1111/j.1600-0838.2007.00657.x

Torstveit, M.K., \& Sundgot-Borgen, J. (2005). Participation in leanness sports but not training volume is associated with menstrual dysfunction: A national survey of 1276 elite athletes and controls. British Journal of Sports Medicine, 39, 141-147. doi:10.1136/bjsm.2003.011338

Vaughan, J., King, K.A., \& Cottrell, R. (2004). Collegiate athletic trainers’ confidence in helping female athletes with eating disorders. Journal of Athletic Training, 39, 71-76.

Yates, A. (1991). Compulsive exercise and the eating disorders. New York: Brunner/Mazel.

Yates, A., Edman, J.D., Crago, M., \& Crowell, D. (2001). Using an exercise based instrument to detect signs of an eating disorder. Psychiatry Research, 105, 231-241. doi: 10.1016/S0165-1781(01)00341-9 
1 Table 1

2 Pattern Matrix of Compulsive Exercise Test Items

\section{Factor}

Item

123

Factor 1 Avoidance of Negative Affect

(20) If I cannot exercise I feel angry and/or frustrated

$\begin{array}{lll}.81 & -.04 & .09\end{array}$

(23) If I cannot exercise I feel anxious

$\begin{array}{lll}.78 & .08 & .08\end{array}$

(10) I feel extremely guilty when I miss an exercise session

$\begin{array}{lll}.76 & .11 & -.05\end{array}$

(22) I feel like I've let myself down if I miss an exercise session

$\begin{array}{lll}.76 & .21 & -.13\end{array}$

(16) If I cannot exercise I feel agitated and/or irritable

$\begin{array}{lll}.69 & -.11 & -.25\end{array}$

(9) If I cannot exercise I feel low or depressed

.67

$-.17$

.15

Factor 2 Weight Control Exercise

(13) I exercise to burn calories and to lose weight

$\begin{array}{lll}-.02 & .86 & .03\end{array}$

(2) I exercise to improve my appearance

$\begin{array}{lll}-.16 & .79 & .17\end{array}$

(6) If I feel I have eaten too much, I will do more exercise

$\begin{array}{lll}.13 & .79 & -.01\end{array}$

(18) If I cannot exercise, I worry that I will gain weight.

$.64 \quad-.09$

Factor 3 Mood Improvement

(1) I feel happier and/or more positive after I exercise

$\begin{array}{lll}-.14 & .12 & .77\end{array}$

(14) I feel less stressed and/or tense after I exercise

$\begin{array}{lll}-.05 & .05 & .73\end{array}$

(17) Exercise improves my mood

$\begin{array}{lll}.17 & -.02 \quad \mathbf{7 0}\end{array}$

(4) I feel less anxious after I exercise

$\begin{array}{lll}.17 \quad .63 & .62\end{array}$

(24) I feel less depressed or low after I exercise

$\begin{array}{lll}.14 & -.06 & .51\end{array}$

Eigenvalue

5.27

2.20

1.51

Variance (\%)

14.67

10.10 
1 Table 2

2 Athlete Norms for the Five Factor and Three Factor Compulsive Exercise Test Subscales

\begin{tabular}{lll}
\hline Subscale & $M(S E)$ & $S D$
\end{tabular}

Avoidance of negative affect (three factor) $2.47(.04)$

1.13

Weight control exercise (three factor)

$2.23(.04)$

Mood improvement (three factor and five factor)

$3.48(.03) \quad 0.87$

Global score (three factor)

$8.18(.09) \quad 2.40$

Avoidance of negative affect and rule driven behaviour (five factor)

$2.51(.04) \quad 1.02$

Weight control exercise (five factor)

$2.33(.04) \quad 1.01$

Exercise rigidity (five factor)

$3.09(.04) \quad 0.95$

Lack of exercise enjoyment (five factor)

$1.45(.03) \quad 0.87$

Global score (five factor)

$12.85(.11)$

2.78

3

4 
1 Table 3

2 Stepwise Regression Analysis Predicting Eating Psychopathology Scores From Three Factor Compulsive Exercise Test Scores in Athletes

\begin{tabular}{|c|c|c|c|c|c|c|c|c|c|c|}
\hline \multirow{2}{*}{ Predictor } & \multicolumn{2}{|c|}{ Global score } & \multicolumn{2}{|c|}{ Restraint } & \multicolumn{2}{|c|}{ Eating concern } & \multicolumn{2}{|c|}{ Shape concern } & \multicolumn{2}{|c|}{ Weight concern } \\
\hline & $\beta$ & $\Delta R^{2}$ & $\beta$ & $\Delta R^{2}$ & $\beta$ & $\Delta R^{2}$ & $\beta$ & $\Delta R^{2}$ & $\beta$ & $\Delta R^{2}$ \\
\hline Model 1 & & $.39^{* * *}$ & & $.28^{* * * *}$ & & $.26^{* * *}$ & & $.38^{* * *}$ & & $.32^{* * *}$ \\
\hline Weight control exercise & $.63^{* * *}$ & & $.53^{* * *}$ & & $.51^{* * *}$ & & $.62^{* * *}$ & & $.57^{* * *}$ & \\
\hline Model 2 & & $.43^{* * *}$ & & $.31^{* * *}$ & & $.29^{* * *}$ & & $.40^{* * *}$ & & $.35^{* * *}$ \\
\hline Weight control exercise & $.55^{* * *}$ & & $.46^{* * *}$ & & $.44^{* * *}$ & & $.56^{* * *}$ & & $.50^{* * *}$ & \\
\hline Avoidance of negative affect & $.21^{* * *}$ & & $.19^{* * *}$ & & $.20^{* * *}$ & & $.17^{* * *}$ & & $.19^{* * *}$ & \\
\hline Model 3 & & $.44^{* * *}$ & & & & $.31^{* * *}$ & & $.42^{* * *}$ & & $.37^{* * *}$ \\
\hline Weight control exercise & $.54^{* * *}$ & & & & $.42^{* * *}$ & & $.54^{* * *}$ & & $.49^{* * *}$ & \\
\hline Avoidance of negative affect & $.20^{* * *}$ & & & & $.19^{* * *}$ & & $.16^{* * *}$ & & $.18^{* * *}$ & \\
\hline Gender & $-.09^{* *}$ & & & & $-.13^{* *}$ & & $-.14^{* * *}$ & & $-.13^{* * *}$ & \\
\hline
\end{tabular}

3 Note. ${ }^{* * *}$ Significant at $p<.001 ;{ }^{* *}$ Significant at $p<.01$ 
Figure 1

Path Diagram for the Original Five Factor Model of the Compulsive Exercise Test

3

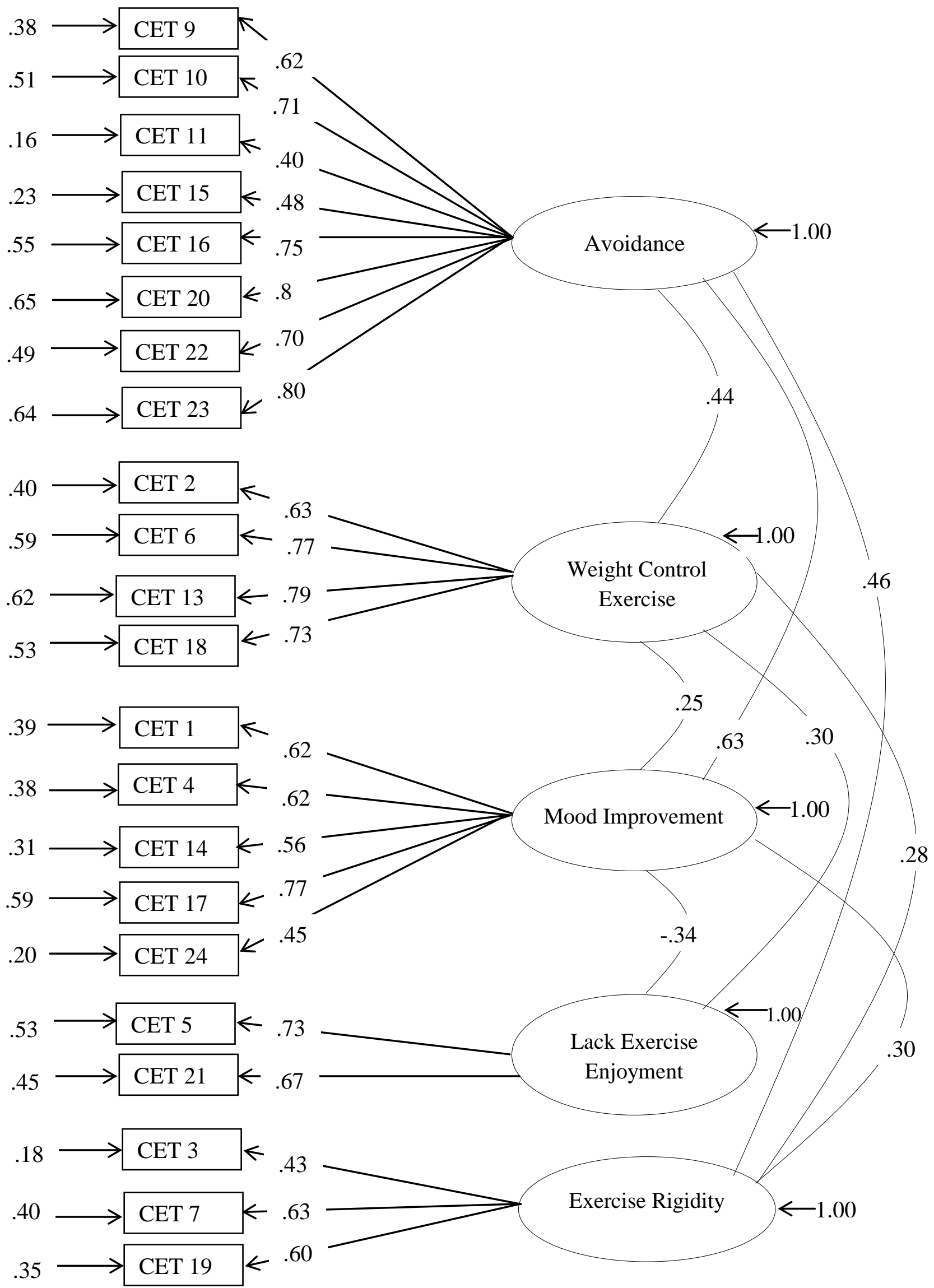

